Published in final edited form as:

Food Nutr Bull. 2011 September ; 32(3): 185-191.

\title{
Meat consumption is associated with less stunting among toddlers in four diverse low-income settings
}

\author{
Nancy F. Krebs, \\ University of Colorado Denver, Aurora, Colorado, USA
}

Manolo Mazariegos,

Institute of Nutrition for Central America and Panama, Guatemala City, Guatemala

Antoinette Tshefu,

Kinshasa School of Public Health, Kinshasa, Democratic Republic of Congo

Carl Bose,

University of North Carolina, Chapel Hill, North Carolina, USA

Neelofar Sami,

Aga Khan University, Karachi, Pakistan

Elwyn Chomba,

University Teaching Hospital, Lusaka, Zambia

Waldemar Carlo,

University of Alabama, Birmingham, Alabama, USA

Norman Goco,

RTI International, Research Triangle Park, North Carolina, USA

Mark Kindem,

RTI International, Research Triangle Park, North Carolina, USA

Linda L. Wright,

Eunice Kennedy Shriver National Institute of Child Health and Human Development, Bethesda, Maryland, USA

K. Michael Hambidge, and

University of Colorado Denver, Aurora, Colorado, USA

the Complementary Feeding Study Group

\section{Abstract}

Background-Early growth faltering is common but is difficult to reverse after the first 2 years of life.

Objective-To describe feeding practices and growth in infants and young children in diverse low-income settings prior to undertaking a complementary feeding trial.

\section{(C) 2011, The United Nations University.}

Please direct queries to the corresponding author: Nancy F. Krebs, University of Colorado Denver, 12700 East 19th Ave, Box C225, Aurora, CO 80045, USA; Nancy.Krebs@ucdenver.edu.

None of the authors of this paper have any financial or contractual agreements that would be considered a conflict of interest with the science presented in this paper, nor are there any products that figure prominently in the submitted manuscript. 
Methods-This cross-sectional study was conducted through the Global Network for Women's and Children's Health Research in Guatemala, Democratic Republic of Congo, Zambia, and Pakistan. Feeding questionnaires were administered to convenience samples of mothers of 5- to 9month old infants and 12- to 24-month-old toddlers. After standardized training, anthropometric measurements were obtained from the toddlers. Following the 2006 World Health Organization Growth Standards, stunting was defined as length-for-age $<-2 \mathrm{SD}$, and wasting as weight-forlength $<-2$ SD. Logistic regression was applied to evaluate relationships between stunting and wasting and consumption of meat (including chicken and liver and not including fish).

Results-Data were obtained from 1,500 infants with a mean ( \pm SD) age of $6.9 \pm 1.4$ months and 1,658 toddlers with a mean age of $17.2 \pm 3.5$ months. The majority of the subjects in both age groups were breastfed. Less than $25 \%$ of the infants received meat regularly, whereas $62 \%$ of toddlers consumed these foods regularly, although the rates varied widely among sites. Stunting rate ranged from $44 \%$ to $66 \%$ among sites; wasting prevalence was less than $10 \%$ at all sites. After controlling for covariates, consumption of meat was associated with a reduced likelihood of stunting $(\mathrm{OR}=0.64 ; 95 \% \mathrm{CI}, 0.46$ to 0.90$)$.

Conclusions-The strikingly high stunting rates in these toddlers and the protective effect of meat consumption against stunting emphasize the need for interventions to improve complementary feeding practices, beginning in infancy.

\section{Keywords}

Complementary feeding; infant growth; infant nutrition; stunting

\section{Introduction}

Stunting of linear growth during childhood is associated with worse health and developmental outcomes in low-income countries [1-3]. Data from the World Health Organization (WHO) indicate that stunting is a pervasive problem in developing countries, although rates are highly variable among countries and regions [4, 5]. In addition, data often are presented as prevalence rates for children under 5 years of age, with less emphasis on rates in younger children. This may be an important omission, because stunting begins early in life [5]. Although the cause of childhood stunting is likely to be multifactorial, infant and child feeding practices and nutritional status are thought to be critical factors [6]. Therefore, information about early rates of stunting, accompanied by data on early childhood feeding practices, may be critical in the development of strategies to reduce stunting and its health consequences.

This is a report of a pilot study conducted in preparation for a multicountry, multicontinent complementary feeding trial by the Global Network for Women's and Children's Health Research (http://gn.rti.org/), supported by the National Institute for Child Health and Human Development (NICHD). The intervention of the trial, for which linear growth velocity is the primary outcome, is daily meat consumption compared with a micronutrient-fortified infant cereal. This pilot study was undertaken in the four participating countries. The objectives of the pilot study were to describe growth, including approximate stunting rates, in 12- to 24month-old toddlers and feeding practices for both infants and toddlers at the participating sites.

\section{Study design and methods Locations}

The pilot study was conducted in four countries of the Global Network for Women's and Children's Health Research: Democratic Republic of Congo, Zambia, Guatemala, and 
Pakistan. The Democratic Republic of Congo communities were in a remote rural location in Equateur Province situated in the far north of the country. In Zambia, the communities were also in rural areas located in the Kafue and Chongwe districts of Lusaka Province. The Guatemalan communities were in small rural towns in the western highlands in the Department of Chimaltenango, and the Pakistan communities were in urban Karachi. The sites were all characterized by low socioeconomic status. Most of the communities in all sites were areas defined by an area served by a health center.

\section{Study design}

This was a cross-sectional descriptive study, with collection of data from two sets of children defined by age. A feeding questionnaire was administered to a convenience sample of mothers of 5- to 9-month-old infants. Measurements of length, weight, and head circumference of 12- to 24-month-old toddlers were recorded, and a different feeding questionnaire was administered to the mothers of these toddlers. Data were collected in at least 10 communities in each country; the same communities were used to collect data for both infants and toddlers.

\section{Subjects}

The subjects were infants ( 5 to 9 months) and toddlers (12 to 24 months) attending clinics for routine visits. Twenty-five to thirty subjects from each group were enrolled in each community. Any child found to be visibly malnourished was referred to a local health facility for care. This study was approved by the Colorado Multiple Institutional Review Board, by the ethics boards of the other US-affiliated universities and of the Data Coordinating Center, Research Triangle Institute, and by the ethics boards in each of the participating countries. The rights of the participants were carefully protected, as described in the Declaration of Helsinki. All caregivers gave written informed consent to participate and permission for their children to participate in the study.

\section{Dietary data and anthropometry}

All sites contributed to the development of common dietary questionnaires for the two age groups. The questionnaires were developed specifically to provide background dietary information considered of particular value for the subsequent feeding trial or to meet specific interests of individual sites. They were not designed to be sufficiently comprehensive to determine dietary diversity nor to be quantitative. For frequency of consumption of foods of interest, the questionnaires offered possible choices of "most days," "1 to 3 times per week," "once a month or less," and "never."

Senior team members from each site were trained in procedures for performing anthropometric measurements and administration of dietary questionnaires. Following a train-the-trainer model, these individuals then trained and certified the field personnel.

Identical equipment for anthropometric measurements was used at all sites. Recumbent length was measured by Seca 416 infantometers accurate to $0.1 \mathrm{~cm}$, naked weight by Salter scales accurate to $120 \mathrm{~g}$, and head circumference by Inser-Tapes graduated to $1 \mathrm{~mm}$. Two measurements were taken for each anthropometric variable. If the two measurements were not in agreement within a prescribed range $(10 \mathrm{~g}$ for weight and $0.4 \mathrm{~cm}$ for recumbent length and head circumference), a third measurement was taken and the two closest values were averaged.

\section{Data analysis}

Basic descriptive analyses were performed according to site and for the entire cohort. Means and standard deviations were calculated for continuous variables, and counts and 
percentages were calculated for categorical variables. Responses to questions on frequency of consumption of foods were collapsed into two categories: most days and 1 to 3 times per week (defined as "regularly") vs. once a month or never. Anthropometric data were characterized by the following Z-scores: length-for-age (LAZ), weight-for-age (WAZ), head circumference-for-age (HCAZ), and weight-for-length (WLZ). These were based on 2006 WHO Growth Standards [7]. Stunting was defined as LAZ $<-2.00$ and wasting as WLZ < -2.00 .

Post hoc analyses were performed to explore associations between dietary patterns and physical growth in the second year of life. Specifically, we used a logistic-type general estimating equation (GEE) model to summarize the relationships between stunting and wasting and consumption of meat (including chicken and liver and not including fish). The model was controlled for age, sex, country of origin, breastfeeding status, and other dietary factors, including the consumption of staples such as cereal, maize, tapioca, rice, potato, cassava, and wheat; peanuts, beans, or insects; store-bought foods; liver; other animalsource foods (fish, dairy, eggs); infant formula; salt (iodized); and mineral supplements, such as zinc and iron. The data were also clustered according to community by an independent correlation structure.

Insufficient information on socioeconomic status was collected during the pilot study to allow the evaluation of outcomes to be adjusted for socioeconomic status (SES), but baseline data from the full complementary feeding study were utilized to characterize SES for 30 of the 64 communities included in the pilot study. Specifically, three economic indicators for these communities-water source, toilet type, and maternal education-were used to generate a community-level water resources score (range, 1 to 6), toilet score (range, 1 to 5), and maternal education score (range, 1 to 8 ) for these 30 communities. We used a two-stage clustering procedure that first implemented linear transformations to standardize the data matrix across the three SES domains and then utilized Ward's minimum variance method on the newly transformed variables to identify clusters of communities that had comparable values across the three SES domains. This clustering procedure indicated that clustering based on these three SES indicators, which were found to be homogeneous within site, provided almost no separation of communities beyond that obtained by knowing the site. Based on these results, which suggest that controlling for site in any model of outcome adequately adjusts for SES, we conducted all analyses with adjustment for site. SAS, version 9.0, was used to perform all analyses.

\section{Results \\ Demographic data}

The number of participating infants at each site ranged from 315 to 531 and the number of toddlers from 336 to 516 (table 1). The mean ages for the two groups were similar across sites and were approximately 7 and 17 months for the infant and toddler groups, respectively. There was an approximately equal sex distribution for the two age groups and across all sites.

\section{Infant dietary data}

Overall, $13.1 \%$ of the 1,500 infants were exclusively breastfed at the time of data collection. Breastfeeding frequency averaged more than 10 times per day, and the rate of formula feeding varied substantially by site but was typically low (table 2). Approximately equal percentages of infants were fed nonbreastmilk complementary foods regularly. Meat was consumed regularly by less than one-quarter of the infants. In contrast, over half the infants received fish, eggs, or dairy regularly. Consumption of legumes (beans and lentils) was 
reported for $45 \%$ of the infants overall. Groundnuts (peanuts) were consumed regularly by more than half of the infants in the African sites but were not consumed regularly in the other two sites.

\section{Toddler dietary data}

Seventy-three percent of the toddlers were still being breastfed at the time of data collection, and only $10.5 \%$ had discontinued breastfeeding before the age of 1 year. Only a small percentage of toddlers received any formula, the highest percentage (31\%) being in Pakistan. The types of grain and other food staples varied somewhat by site, but overall, maize, rice, and potatoes were reported to be consumed by at least $80 \%$ of the subjects. Beans or lentils were also fed on most days to the majority of infants, ranging from $74 \%$ to $97 \%$ among sites. In contrast to the infants, the majority of toddlers received animal-source foods, with $62 \%$ eating meat regularly. This percentage varied by site, from $15 \%$ in Democratic Republic of Congo to $91 \%$ in Guatemala. Other animal-source foods (fish, milk, or eggs) were given to $90 \%$ of the toddlers. Overall, $55 \%$ of toddlers were fed some storebought foods, the percentage ranging from 6\% in Democratic Republic of Congo to 88\% in Guatemala. The rate of regular micronutrient supplement use also ranged widely, from less than $1 \%$ in Democratic Republic of Congo to 77\% in Guatemala, where iron-folate supplements are mandated by the Ministry of Health.

\section{Toddler anthropometric data}

The mean LAZ for the entire cohort was more than 2 SD below the normalized population average of the WHO standards, ranging among sites from -1.9 to -2.8 (table 3). Mean WAZ and HCAZ were both negative for the entire cohort and at each site but overall were closer to $1 \mathrm{SD}$ below the median. The mean WLZ was -0.32 for the entire cohort and was positive for two sites. Anthropometric values were essentially the same for girls and boys, and there were no consistent sex differences among sites (data not shown). The overall stunting rate was $53 \%$, with a range of $44 \%$ to $66 \%$ across the sites (fig. 1A). In contrast to stunting, the wasting rate was $5.9 \%$ overall and was less than $10 \%$ for all sites (fig. 1B).

\section{Predictors of stunting and wasting}

After controlling for covariates, consumption of meat was associated with reduced likelihood of stunting ( $\mathrm{OR}=0.64 ; 95 \% \mathrm{CI}, 0.46$ to 0.90$)$. Consumption of iodine ( $\mathrm{OR}=$ $0.74 ; 95 \% \mathrm{CI}, 0.57$ to 0.95$)$ was also associated with lower stunting rates. Age (OR $=1.10$; $95 \% \mathrm{CI}, 1.06$ to 1.14$)$, sex (OR $=0.71 ; 95 \% \mathrm{CI}, 0.58$ to 0.88$)$, and country of origin ( $p=$. 02 ) were also significantly associated with stunting and were the only other covariates for which this was true.

Eating meat was also associated with reduced likelihood of wasting ( $\mathrm{OR}=0.50 ; 95 \% \mathrm{CI}$, 0.26 to 0.94$)$. The only other covariate that significantly predicted wasting was country of origin $(p=.002)$.

\section{Discussion}

The primary objective of this study was to describe growth, including stunting rates, among toddlers in impoverished populations in four developing countries. A secondary objective was to characterize feeding practices that might contribute to growth failure. Three important findings emerged from this analysis. First, remarkably high stunting rates were observed in all sites, but particularly in Democratic Republic of Congo and Guatemala, where nearly two-thirds of the toddlers were stunted. Second, regular consumption of meat was associated with a significantly reduced risk of stunting. Finally, in contrast to stunting, wasting rates were low. 
The high rates of stunting observed in our study exceed some previous estimates. For example, regional prevalence rates of stunting in children under 5 years of age of $40 \%$ in Southern Asia, 40\% in Africa, and 23\% in Central America have been described [6]. These rates predict that more than 175 million children suffer from stunting worldwide each year. Our data suggest that this number may be even higher.

Our observation that wasting rates were low relative to stunting rates is in agreement with previous reports. Although the magnitude of wasting rates varies among studies, virtually all recent data from diverse settings have also reported wasting to be much less prevalent than stunting [6, 8-10]. Declines in weight-for-age over this age range [11] are accounted for in large part by the decline in length-for-age. Such observations suggest that in the absence of circumstances of overt starvation (e.g., during war or natural disasters), the malnutrition experienced by infants and young children in developing countries probably results primarily from micro-nutrient deprivation rather than calorie deprivation.

The etiology of stunting is multifactorial, including preconceptional, prenatal, and postnatal factors, but malnutrition may have a major role in each phase. Recent reports have persuasively demonstrated that growth retardation typically begins during the first year of life $[5,8-10,12,13]$. However, the highest rates of stunting have been observed among children between 12 and 24 months of age [9], a finding consistent with our observation of age being significantly positively associated with stunting in toddlers. Stunting rates appear to plateau thereafter [6]. These observations suggest that in areas with high stunting rates, feeding practices and diet quality have an important impact on growth in infants between 6 and 12 months of age $[10,13,14]$ and that postnatal factors progressively impair linear growth. In turn, this implies that effective interventions should begin in infancy to potentially reverse early growth faltering and prevent progressive deterioration in the rate of growth.

The predominance of breastfeeding and the relatively low use of micronutrient-fortified foods or formulas predict a high risk of micronutrient deficiencies, especially iron and zinc [15-17]. The absence of regular meat consumption in $80 \%$ of the infants may further increase the risk of these micronutrient deficiencies. The factors in this study that were found to be associated with a decrease in the prevalence of stunting may be important in the development of strategies to reduce stunting. Most prominent among these factors was feeding meat at least one to three times per week. Animal products are recognized as a vital component of complementary feeding for older infants and young children [14, 16, 18], especially for those children who do not have access to a regular supply of micronutrientfortified products. Studies that have examined dietary patterns in older infants in relation to stunting have emphasized the importance of nutrient-dense complementary foods, including animal-source foods, to meet infants' nutrient requirements and to improve growth outcomes $[10,13,14,16]$.

Among the well-recognized nutritional contributions of animal foods, notably meats, are zinc, iron, vitamin $\mathrm{B}_{12}$, and other micronutrients, but it is likely that other aspects of the nutrient profile provided by meat are also beneficial. The advantages, potential or demonstrated, of including meat as a complementary food for infants and toddlers have been the focus of recent reviews [17, 19], and the inclusion of meat has been recommended by WHO [18]. Our observation that the consumption of meat was associated with improved growth suggests that strategies to improve the intake of flesh foods might reduce the rate of stunting in these sites. Although randomized, controlled trials specific to meat consumption are limited, educational interventions in developing countries have demonstrated positive effects of dietary diversification, including meat consumption, on stunting rates [20-22]. The significant inverse relationship observed in the current study between the prevalence of 
stunting and the use of iodized salt is another example of the importance of dietary quality and serves as a reminder that iodine deficiency is regrettably still widespread in sub-Saharan Africa, especially in those countries that have not legislated the addition of iodine to all salt.

A limitation of this study is the absence of longitudinal growth and dietary data. Since at each site the infants resided in the same communities as the toddlers, some inferences can reasonably be made. As discussed above, the infants in these areas were likely to be at risk for growth faltering, especially stunting, which typically starts in the first year of life [5]. The dietary surveys we constructed also did not quantify nutrient intakes or provide a complete picture of dietary diversity. The predominance of cereal grains and legumes, however, is similar to that in other reports of complementary foods for infants in this age range in comparable settings [14, 23].

The limited information on the SES of the participants is also a shortcoming of the study. Although meat consumption may be associated with other household resources that would impact growth, the two are not necessarily correlated. Inadequate knowledge about appropriate foods and feeding practices is often a greater determinant of malnutrition than the lack of food [24]. Surveys of infant feeding in the United States consistently report that meat is among the last foods to be introduced to older infants, irrespective of household income status [25, 26]. Additionally, higher household income is not always associated with reduced stunting [27].

The use of meat for infants and young children poses major challenges, but none are necessarily insurmountable. Ground or pureed meats have been shown to be well accepted by infants as young as 6 months of age [28] and in some cultures are routinely offered at this age [14]. The expense of meats is often cited as a major barrier to their use for infants, but the fact that the majority of toddlers in our study consumed meat several times per week suggests that at least modest amounts of meat are available in many households. Thus, rather than a lack of availability, the barrier to the use of meat may be attitudes about its earlier initiation in infants' diets. Clearer understanding that early stunting is associated with short adult stature and limited cognitive potential and that meat consumption is associated with improved linear growth in children may lead to better acceptance of the incorporation of meat into the diet of this target population.

In summary, the outstanding findings in this study include the very high prevalence of stunting in young children in four diverse settings (ranging from $44 \%$ to $66 \%$ ) and the observation that regular meat intake by toddlers was the most prominent factor associated with a protective effect against stunting. These results provide a solid rationale for proceeding with the current NICHD-supported randomized, controlled trial of meat as a first complementary food. Such an intervention will address the current critical gap in the evidence base for feeding guidelines and their effect on growth outcomes.

\section{Acknowledgments}

The Complementary Feeding Group consists of Ana Garces (Instituto Multidisciplinario para la Salud, Guatemala City, Guatemala); Jamie Westcott (University of Colorado Denver, Aurora, Colorado, USA); Adrien Lokangaka (Kinshasa School of Public Health, Kinshasa, Democratic Republic of Congo); Omrana Pasha (Aga Khan University, Karachi, Pakistan); Robert Goldenberg (Drexel University, Philadelphia, Pennsylvania, USA); Albert Manasyan, Edna Imenda and Melody Kunda (University Teaching Hospital, Lusaka, Zambia); and Elizabeth McClure, Abhik Das, and Tyler Hartwell (RTI International, Research Triangle Park, North Carolina, USA). This project was supported by the Global Network for Women's and Children's Health Research (NICHD U01 HD040657). 


\section{References}

1. Sigman M, Neumann C, Baksh M, Bwibo N, McDonald MA. Relationship between nutrition and development in Kenyan toddlers. J Pediatr. 1989; 115:357-64. [PubMed: 2769494]

2. Walka H, Pollitt E. A preliminary test of a developmental model for the study of undernourished children in Indonesia. Eur J Clin Nutr. 2000; 54 (suppl 2):S21-7. [PubMed: 10902984]

3. Olney DK, Kariger PK, Stoltzfus RJ, Khalfan SS, Ali NS, Tielsch JM, Sazawal S, Black R, Allen LH, Pollitt E. Development of nutritionally at-risk young children is predicted by malaria, anemia, and stunting in Pemba, Zanzibar. J Nutr. 2009; 139:763-72. [PubMed: 19225131]

4. Van de Poel E, Hosseinpoor AR, Speybroeck N, Van Ourti T, Vega J. Socioeconomic inequality in malnutrition in developing countries. Bull World Health Organ. 2008; 86:282-91. [PubMed: 18438517]

5. Victora CG, de Onis M, Hallal PC, Blossner M, Shrimpton R. Worldwide timing of growth faltering: revisiting implications for interventions. Pediatrics. 2010; 125:e473-80. [PubMed: 20156903]

6. Black RE, Allen LH, Bhutta ZA, Caulfield LE, de Onis M, Ezzati M, Mathers C, Rivera J. Maternal and child undernutrition: global and regional exposures and health consequences. Lancet. 2008; 371:243-60. [PubMed: 18207566]

7. World Health Organization. The WHO child growth standards. Geneva: WHO; 2006.

8. Hien NN, Kam S. Nutritional status and the characteristics related to malnutrition in children under five years of age in Nghean, Vietnam. J Prev Med Public Health. 2008; 41:232-40. [PubMed: 18664729]

9. Fenn B, Penny ME. Using the new World Health Organisation growth standards: differences from 3 countries. J Pediatr Gastroenterol Nutr. 2008; 46:316-21. [PubMed: 18376251]

10. Umeta M, West CE, Verhoef H, Haidar J, Hautvast JG. Factors associated with stunting in infants aged 5-11 months in the Dodota-Sire District, rural Ethiopia. J Nutr. 2003; 133:1064-9. [PubMed: 12672920]

11. Shrimpton R, Victora CG, de Onis M, Lima RC, Blossner M, Clugston G. Worldwide timing of growth faltering: implications for nutritional interventions. Pediatrics. 2001; 107:E75. [PubMed: 11331725]

12. Hambidge M, Mazariegos M, Kindem M, Wright LL, Cristobal-Perez C, Juárez-García L, Westcott J, Goco N, Krebs NF. Infant stunting is associated with short maternal stature in Guatemala. J Pediatr Gastro Nutr. Submitted for publication. in press.

13. Kimmons JE, Dewey KG, Haque E, Chakraborty J, Osendarp SJ, Brown KH. Low nutrient intakes among infants in rural Bangladesh are attributable to low intake and micronutrient density of complementary foods. J Nutr. 2005; 135:444-51. [PubMed: 15735076]

14. Ruel MT, Menon P. Child feeding practices are associated with child nutritional status in Latin America: innovative uses of the demographic and health surveys. J Nutr. 2002; 132:1180-7. [PubMed: 12042431]

15. World Health Organization. Complementary feeding of young children in developing countries: a review of current scientific knowledge. Geneva: WHO; 1998.

16. Dewey KG, Brown KH. Update on technical issues concerning complementary feeding of young children in developing countries and implications for intervention programs. Food Nutr Bull. 2003; 24:5-28. [PubMed: 12664525]

17. Krebs NF, Hambidge KM. Complementary feeding: clinically relevant factors affecting timing and composition. Am J Clin Nutr. 2007; 85:639S-45S. [PubMed: 17284770]

18. Pan American Health Organization/World Health Organization. Guiding principles for complementary feeding of the breastfed child. Washington, DC: PAHO/WHO; 2003.

19. Hambidge, KM.; Krebs, NF. Zinc deficiency: A special challenge. J Nutr; Symposium on FoodBased Approaches to Combating Micronutrient Deficiencies in the Developing World; 2007. p. 1101-5.

20. Penny ME, Creed-Kanashiro HM, Robert RC, Narro MR, Caulfield LE, Black RE. Effectiveness of an educational intervention delivered through the health services to improve nutrition in young children: a cluster-randomised controlled trial. Lancet. 2005; 365:1863-72. [PubMed: 15924983] 
21. Guldan GS, Fan HC, Ma X, Ni ZZ, Xiang X, Tang MZ. Culturally appropriate nutrition education improves infant feeding and growth in rural Sichuan, China. J Nutr. 2000; 130:1204-11. [PubMed: 10801920]

22. Shi L, Zhang J, Wang Y, Caulfield LE, Guyer B. Effectiveness of an educational intervention on complementary feeding practices and growth in rural China: a cluster randomised controlled trial. Public Health Nutr. 2010; 13:556-65. [PubMed: 19706219]

23. Bhutta ZA. Iron and zinc intake from complementary foods: some issues from Pakistan. Pediatrics. 2000; 106:1295-7. [PubMed: 11061841]

24. World Health Organization. Global strategy for infant and young child feeding. Geneva: WHO; 2003.

25. Grummer-Strawn LM, Scanlon KS, Fein SB. Infant feeding and feeding transitions during the first year of life. Pediatrics. 2008; 122(suppl 2):S36-42. [PubMed: 18829829]

26. Fox MK, Pac S, Devaney B, Jankowski L. Feeding Infants and Toddlers Study: what foods are infants and toddlers eating? J Am Diet Assoc. 2004; 104:s22-30. [PubMed: 14702014]

27. Godoy R, Nyberg C, Eisenberg DT, Magvanjav O, Shinnar E, Leonard WR, Gravlee C, ReyesGarcia V, McDade TW, Huanca T, Tanner S. Short but catching up: statural growth among native Amazonian Bolivian children. Am J Hum Biol. 2010; 22:336-47. [PubMed: 19844899]

28. Krebs NF, Westcott JE, Butler N, Robinson C, Bell M, Hambidge KM. Meat as a first complementary food for breastfed infants: feasibility and impact on zinc intake and status. $\mathrm{J}$ Pediatr Gastroenterol Nutr. 2006; 42:207-14. [PubMed: 16456417] 
A

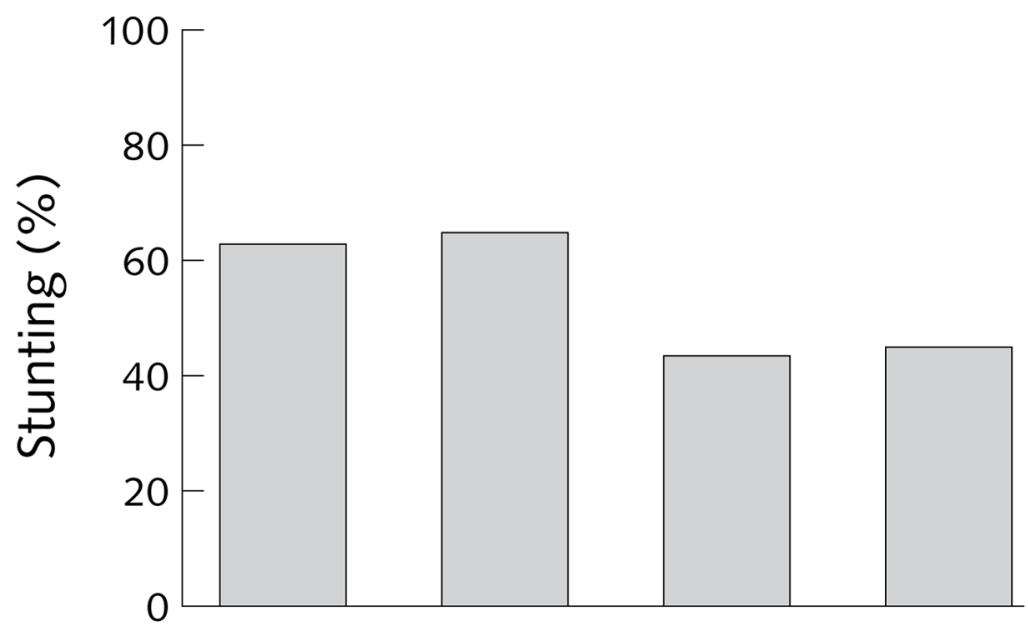

B

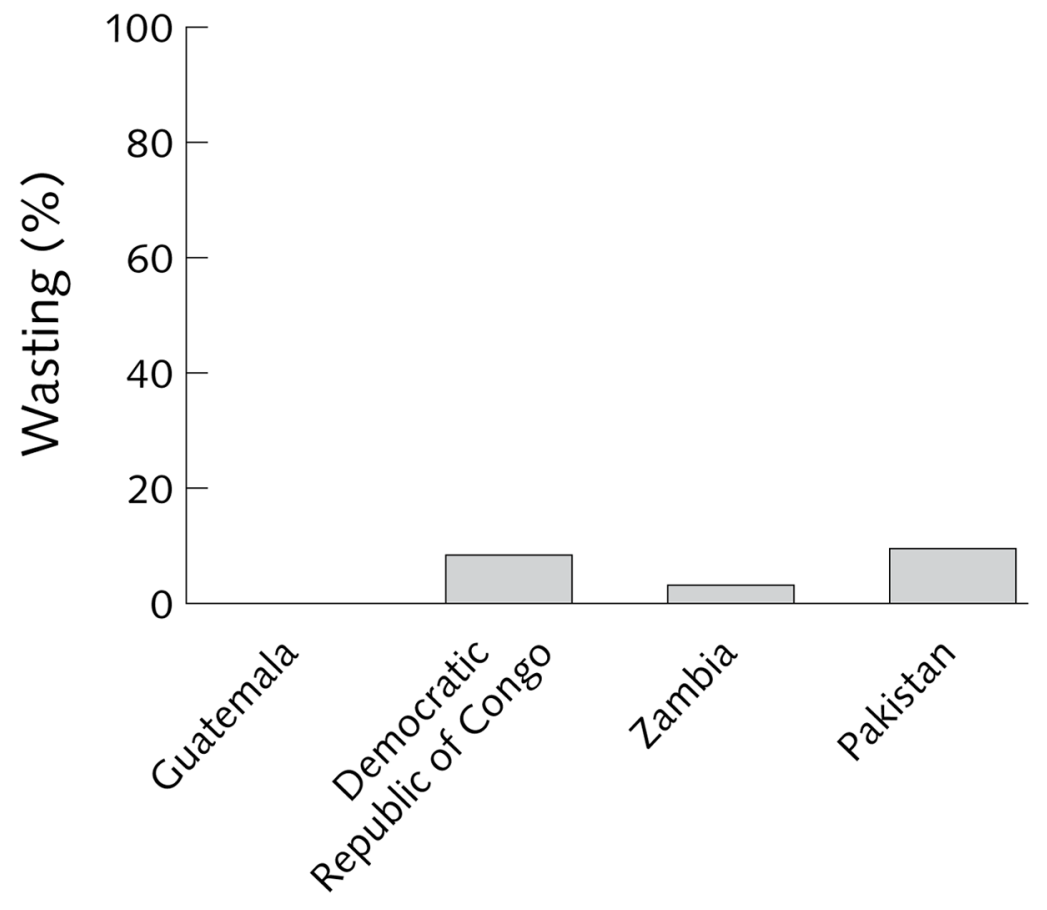

FIG. 1.

Rates of stunting (A) and wasting (B) by site 


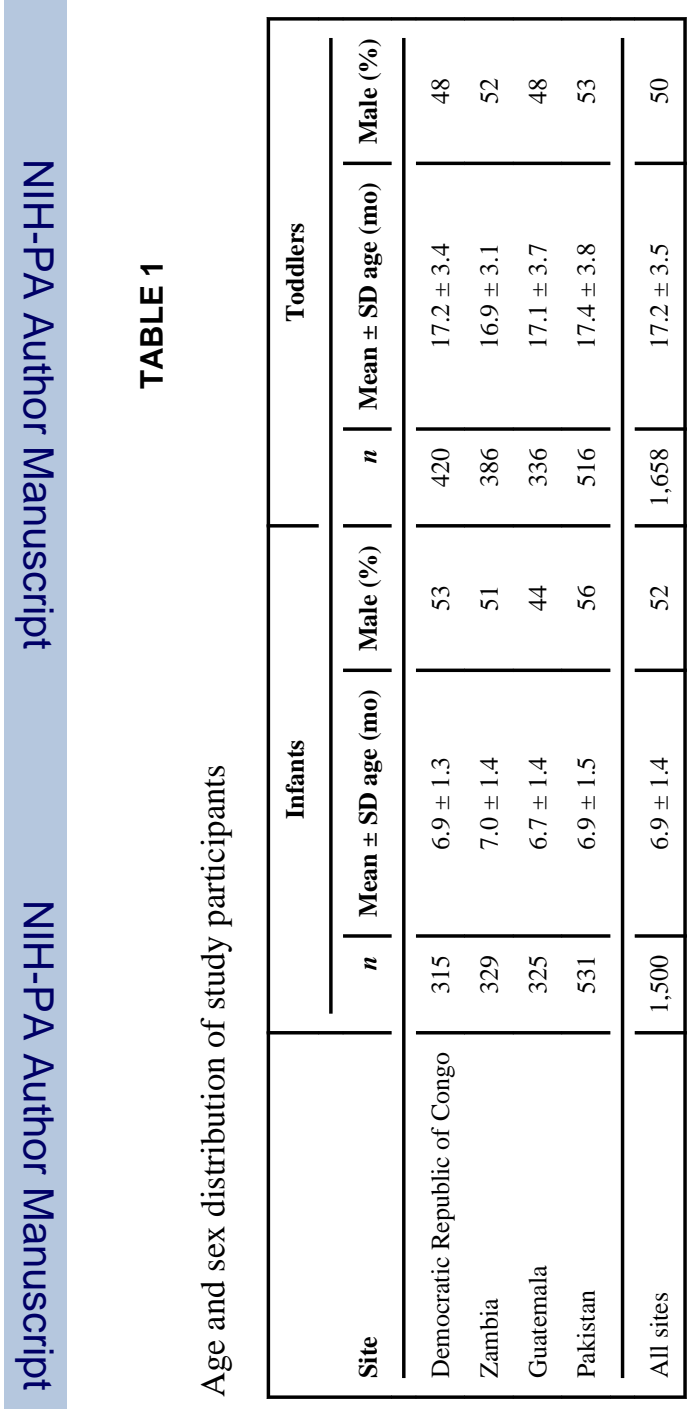

Food Nutr Bull. Author manuscript; available in PMC 2014 February 10. 


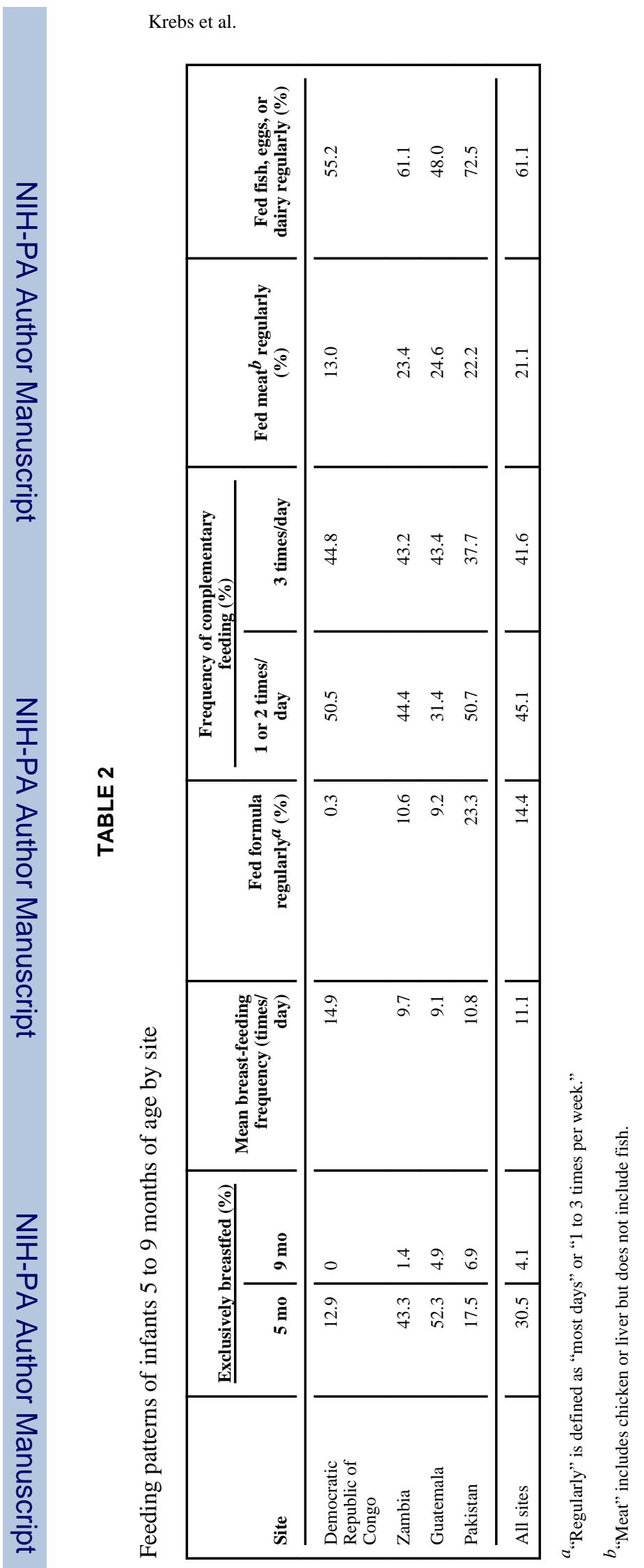

Food Nutr Bull. Author manuscript; available in PMC 2014 February 10. 


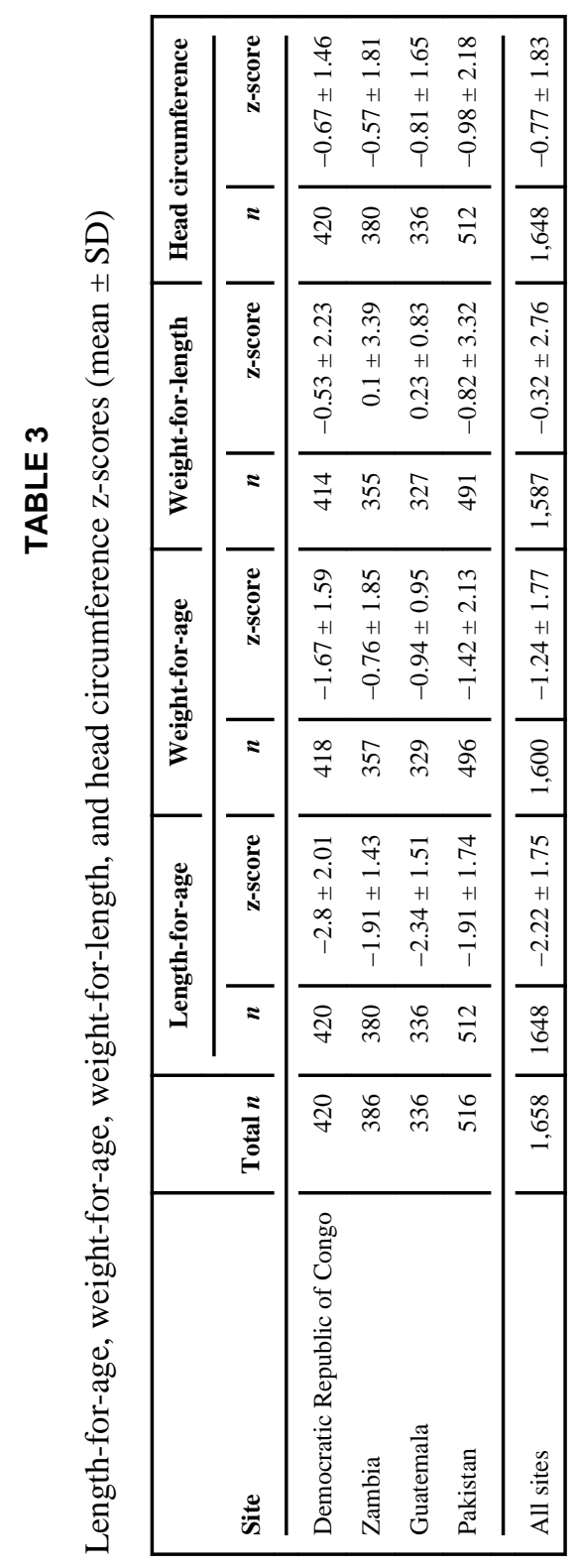

Food Nutr Bull. Author manuscript; available in PMC 2014 February 10. 